\title{
3D FINITE ELEMENT SIMULATION OF CUTTING FORCES IN MILLING HARDENED STEELS
}

\author{
M. $\operatorname{Imad}^{1}$, A. Hosseini ${ }^{1 *}$, H.A. Kishawy ${ }^{1}$, N.Z. Yussefian ${ }^{2}$ \\ ${ }^{1}$ Department of Automotive, Mechanical, and Manufacturing Engineering, Faculty of Engineering and Applied Science, \\ Ontario Tech University, Oshawa, Canada \\ ${ }^{2}$ Sandvik Coromant Research and Development, Lerkrogsvagen 19, Hagersten, Stockholm, Sweden \\ *sayyedali.hosseini@uoit.ca
}

\begin{abstract}
The presented work proposes a numerical 3D finite element model that is able to predict cutting forces, in hard milling of AISI 4340 steel. The numerical 3D finite element model was developed using ABAQUS/Explicit 2020 software and is based on the Lagrangian approach. Johnson-Cook strength and fracture models were adopted, to simulate the elastoplastic with isotropic hardening behavior of the workpiece material. Material's flow stress was defined in terms of strain, strain rate, and temperature. Machining tests were also carried out to verify the proposed numerical model. The close agreement between the simulated cutting forces and those that were obtained experimentally from machining tests verified the accuracy of the proposed numerical model. Chips were also collected during the machining tests and were compared to the numerically simulated ones to add another layer of validity check to the proposed numerical model.
\end{abstract}

Keywords; numerical simulation, 3D finite element modelling, milling, hardened steel, cutting forces, serrated chips.

\section{INTRODUCTION}

Hard milling using indexable milling cutters is a widely used machining process. Machining, also known as material/metal removal process, is a process in which a layer of material, mainly metal, is removed by means of a wedge shape cutting tool. Due to the presence of variety of factors such as high strain, high strain rate, and high temperature, analytical modelling and simulation of material behavior during machining is a challenging task. A common approach to tackle this issue is implementing numerical models. These models are not only useful for analyzing machining processes, but also critical during the design and development phase of new cutting tools. Numerical Finite Element Analysis (FEA) models, are able to simulated complex boundary conditions for various material models [1]. In addition, FEA models present greater detailed results in terms of understanding metal cutting processes, in comparison to analytical models [1]. FEA models introduce the ability to evaluate and capture thermo-mechanical properties of the workpiece and the tool during machining processes. Such properties are difficult or not possible to be captured during experimental testing [2]. The utilization of FEA enables users to capture the following properties: stress/strain distributions, temperature distribution (within the interface between tool/workpiece), residual stresses, cutting forces, and various other properties [1]. Those properties help to understand the behavior of the tool/workpiece material under high strains, high strain rates, and high temperatures. These properties allow tool designers to minimize the chances of unpredictable failures during the metal cutting operation. Also, FEA models eliminate the need to understand the behavior of tool/workpiece from expensive experimental tests. This reduces the operational cost and minimizes the required labor [2]. Furthermore, it allows operators to choose desirable cutting conditions for an optimum machining process in terms of power consumption, tool wear, and material removal efficiency [3].

The goal of this work is to present a 3D FEA model for milling of hardened AISI 4340 steel using indexable cutters. The model is able to simulate cutting forces and chip formation during milling operations. ABAQUS/Explicit 2020 was utilized to present the numerical model. The presented model was validated by establishing a correlation between simulated cutting forces and chip types, with the conducted experimental investigations.

\section{LITREATURE REVIEW}

Milling numerical models can be broken down into 2D and 3D models. However, 2D FEA models consider various assumptions. The main assumption $2 \mathrm{D}$ models consider is a plain strain deformation [4]. This assumption is applicable in specific milling operational conditions. The conditions include, when the radial depth of cut is much larger than the milling insert's nose radius [4]. Nevertheless, in many milling situations these conditions are not applicable. The various assumptions of 2D numerical models, have paved the way for researchers' interest in developing 3D milling models. Pittalà et al. [4], developed a 3D FEA model for a face milling operation using indexable inserts. DEFORM-3D was utilized as the FEA software to develop the model. The real geometry of the indexable insert was investigated. Their model was able to predict cutting forces for a 6000 series aluminum alloy. Also, the 
model presented reasonable results when compared to experimental cutting force data. Soo et al. [5], established a 3D FEA model for a high-speed solid ball nose end milling operation of the nickel-based super alloy, Inconel 718. The FEA model was a Lagrangian-based model and it considered the condition of full immersion. ABAQUS/Explicit was used to create the model. Then, it was validated by comparing it against similar cutting conditions experimentally. The numerical model forces in the feed and step over direction were within $10 \%$ from the captured experimental forces. However, the thrust (axial) force presented an error of $\sim 90 \%$ from the experimental results. The discrepancy, was reasoned due to the used technique of element deletion. The technique removed the contact between the newly machined surface and the tool's cutting edge. Removing the contact removed the reacting forces. In addition, the predicted temperature within the primary shear zone was validated with experimental data. The model's temperature prediction results were within $5 \%$ from the experimental data. Wu et al. [6], obtained Johnson-Cook (J-C) constitutive equation constants for titanium alloy Ti6Al4V experimentally. Then, ABAQUS/Explicit was utilized as the software to develop a 3D FEA milling operation model. The FEA model was developed for solid end milling processes. The proposed model was able to obtain multiple properties. Properties included: produced chips, generated stresses, cutting forces, and temperature distributions. Authors, validated their model by conducting experimental tests. As a conclusion, a correlation between the obtained experimental forces and generated numerical forces was established. Thepsonthi and Özel [2], proposed FEA 3D models for the micro-end milling of titanium alloy Ti6Al4V, using DEFORM-3D. The models examined the effects of increasing solid cutting tools' edge roundness. Edge roundness increase was investigated due to its impact on the development of tool wear during milling operations. For the examination process, up/down milling kinematics during half immersion, full immersion radial depth of cuts (RDOCs), and slot micro-end milling were considered. Models were then validated, by presenting a good agreement between chip shapes as well as the development of tool wear with experimental tests of similar conditions. Zhang et al. [7], built a 3D FEA model to investigate the nonlinear behavior of AISI H13 steel during its hard milling operation, by utilizing ABAQUS/Explicit software. The model's generated forces were validated with experimental data. As a result, a good agreement between both data was established. Later, authors investigated the effects of cutting speeds and feed rates on cutting forces and cutting temperatures.

Most of the finite element models of milling operations are either 2D orthogonal models or $3 \mathrm{D}$ in software such as DEFORM-3D or AdvantEdge. The presented model in this paper is built in ABAQUS/Explicit. It offers more flexibility in defining the material strength and fracture properties; thus, delivers a more realistic presentation of the process.

\section{NUMERICAL INVESTIGATION}

\section{A. 3D FEA Model}

A 3D finite element model for hardened AISI 4340 steel (47 \pm 1 HRC) is proposed in this work. The 3D model was established using ABAQUS/Explicit 2020 FEA solver. The proposed model duplicated the same setup as the experimental setup. The workpiece consisted of a 345312 C3D8RT elements. Meshing impacts the accuracy of the results, thus the meshes in the cutting regions were refined and made finer than the rest of the workpiece. Cutting insert was also modeled in the same solver, because when the cutting insert was modeled in a different Computer Aided Design (CAD) software, and imported into ABAQUS/Explicit 2020, errors were experienced. Main geometrical parameters were included in the modeling of the insert. Half of the insert (in length) was modeled. The reason for that is due to the fact that, only $10 \%$ of the axial cutting edge was in contact with the workpiece. Furthermore, the reaming half was not needed for the insert's structural support, because it was modeled as a rigid body. The rigid insert consisted of 1846 C3D10M elements. Fig. 1 shows the assembly of the cutting insert and the workpiece. For optimizing the use of computational power, only the half immersion area in which the chip would be generated was included in the model, and the remaining portion of the workpiece was removed. This lowers the number of elements and improves the computational time.

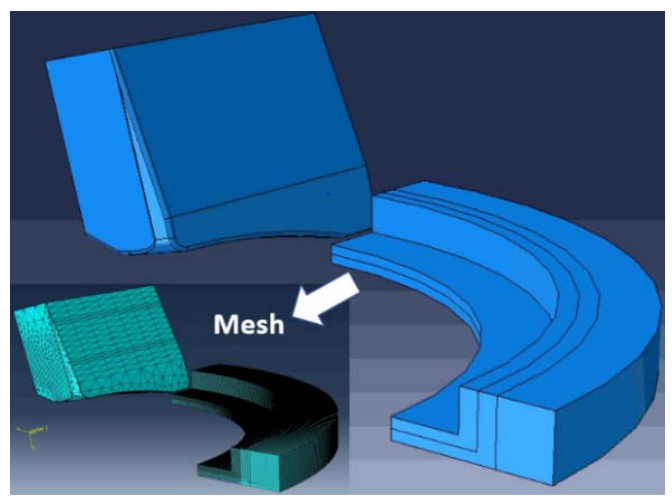

Figure 1. Cutting insert and workpiece assembly in ABAQUS/Explicit

\section{B. Material Modelling}

Table 1 illustrates the general material properties of AISI 4340 (47 \pm 1 HRC). However, due to the physics of milling process, J-C material strength model was adopted to represent the von Mises flow stress of the material [8]. Equation (1) represents the strength model in which $\sigma$ is the material's Von Mises flow stress. The equation has three main terms representing the effects of strain, strain rate, and temperature.

TABLE I. WORKPIECE MATERIAL Properties [9]

\begin{tabular}{|c|c|}
\hline Parameter & Value \\
\hline Young Modulus $(E)$ & $205(\mathrm{GPa})$ \\
\hline Poisson's Ratio $(v)$ & 0.3 \\
\hline Density & $7850\left(\mathrm{Kg} / \mathrm{m}^{3}\right)$ \\
\hline Specific Heat & $475(\mathrm{~J} / \mathrm{KgK})$ \\
\hline Thermal Conductivity & $44.5(\mathrm{~W} / \mathrm{mK})$ \\
\hline Thermal Expansion & $13.7(\mu \mathrm{m} / \mathrm{mK})$ \\
\hline
\end{tabular}

$$
\sigma=\left[A+B \varepsilon^{n}\right]\left[1+C \ln \dot{\varepsilon}^{*}\right]\left[1-T^{* m}\right]
$$

The first term of the flow stress equation is the strain term and is presented by $\left[A+B \varepsilon^{n}\right]$. The equivalent plastic strain $\varepsilon$, 
represents the materials plastic deformation. This term is dimensionless and tends to be used for elastoplastic materials. The constant $A$ is the yield stress. The flow stress is equal to the constant $A$ when $\varepsilon=0$. This indicates that material elastically deforms and any value above zero represents the plastic deformation. The constant $B$ is the strain hardening coefficient which is equivalent to true stress when the true strain is at unity [10]. Constants $A$ and $B$ both are in MPa. The final constant of the flow stress equation is the dimensionless constant $n$, which is the strain-hardening exponent. Terms $A, B, n$ are experimentally acquired constants.

The second term of the flow stress equation is the strain rate term and is presented by $\left[1+C \ln \dot{\varepsilon}^{*}\right]$. This term includes $\dot{\varepsilon}^{*}$ the dimensionless plastic strain rate and the constant $C$. The dimensionless plastic strain is calculated in terms of the strain rate during the simulation and the experiment. $\dot{\varepsilon}$ is the dimensionless plastic strain rate and it is given per unit of time $s^{-1}$. The referenced strain rate $\dot{\varepsilon}_{o}$ is also dimensionless per unit of time $\mathrm{s}^{-1}$ as shown in (2). The constant $C$ is the strain sensitivity parameter and it is obtained experimentally.

$$
\dot{\varepsilon}^{*}=\frac{\dot{\varepsilon}}{\dot{\varepsilon_{o}}}
$$

The third term is the temperature term and it is presented in the flow stress equation by $\left[1-T^{* m}\right]$. This term includes the homologous temperature $T^{*}$ and the thermal sensitivity constant $m$. The homologous temperature is presented in (3).

$$
T^{*}=\frac{T-T_{\text {Reference }}}{T_{\text {Melting }}-T_{\text {Reference }}}
$$

The homologues temperature is dimensionless and its value is a decimal between zero and unity. It is given in terms of the materials temperature $T$, referenced temperature $T_{\text {Reference }}$, and the melting temperature of the material $T_{\text {Melting }}$. Generally, the reference temperature is chosen as the room temperature (in this paper $T_{\text {Reference }}=20^{\circ} \mathrm{C}$ ). Similar to other constants, the thermal softening constant $m$ is experimentally obtained.

\section{Fracture Modelling}

The J-C Fracture model takes into consideration the fracture characteristics of materials [11]. This feature enables users to use coarse mesh size, and save computational resources without the need to identify the initial shape of the chip. The analytical representation of the fracture model is presented in (4). Where $D$ is the damage parameter and it is equal the division of the summations of the equivalent plastic strains $\Delta \varepsilon$ during the simulation, over the equivalent fracture strain $\varepsilon^{f}$. The fracture of the material during a numerical simulation is initiated when the damage parameter is equal to unity $D=1$. The increment of the equivalent plastic strain is calculated during the execution of the simulation. The equivalent fracture strain is presented by (5), and considers the stress triaxiality ratio, strain rate, and the temperature.

$$
D=\sum \frac{\Delta \varepsilon}{\varepsilon^{f}}
$$

The stress triaxiality term of the equivalent fracture strain is represented by $\left[D_{1}+D_{2} e^{D_{3} \sigma^{*}}\right]$ The term $\sigma^{*}$ is the dimensionless stress triaxiality and it is represented in (6). The stress triaxiality is defined as the ratio of the average of three normal stress $\sigma_{m}$ to the von Mises equivalent stress $\bar{\sigma}$. Other notable researchers have presented stress triaxiality models as shown in (7) [12]. In Bridgman's stress triaxiality equation $R(\mathrm{~mm})$ is the radius of the necked region and $a(\mathrm{~mm})$ is the minimum cross-sectional area of the tested specimen. $D_{1}, D_{2}, D_{3}$ are experimentally obtained constants.

$$
\begin{gathered}
\varepsilon^{f}=\left[D_{1}+D_{2} e^{D_{3} \sigma^{*}}\right]\left[1+D_{4} \dot{\varepsilon}^{*}\right]\left[1+D_{5} T^{*}\right] \\
\sigma^{*}=\frac{\sigma_{m}}{\bar{\sigma}} \\
\sigma^{*}=0.3 \ln \left(1+\left(\frac{a}{2 R}\right)\right)
\end{gathered}
$$

The second term of the equivalent strain to fracture equation includes the dimensionless plastic strain rate $\dot{\varepsilon}^{*}$ and the constant $D_{4}$. The dimensionless plastic strain is calculated in terms of the strain rate during simulation and the experimental $\dot{\varepsilon}$. The plastic strain rate is given dimensionless per unit of time $s^{-1}$. The referenced strain rate $\dot{\varepsilon}_{o}$ is also dimensionless unit per unit of time $\mathrm{s}^{-1}$. The term $\dot{\varepsilon}^{*}$ is calculated in the same manner at the J-C Strength model's flow stress equation which is represented in (2). The constant $D_{4}$ is obtained experimentally.

The third term is the temperature term and presented by $\left[1+D_{5} T^{*}\right]$ This term includes the homologous temperature $T^{*}$ and the experimentally obtained constant $D_{5}$. The homologous temperature is presented in (3) and is calculated in the same manner as the J-C Strength model equation. Table 2 and table 3 displays the used J-C strength and fracture model's constants, respectively.

TABLE II. J-C StREngth Model’s COnstants [1]

\begin{tabular}{|c|c|}
\hline Parameter & Value \\
\hline$A$ & $950(\mathrm{MPa})$ \\
\hline$B$ & $725(\mathrm{MPa})$ \\
\hline$C$ & 0.015 \\
\hline$n$ & 0.375 \\
\hline$m$ & 0.625 \\
\hline$\dot{\varepsilon}_{o}$ & $3,500 \mathrm{~s}^{-1}$ \\
\hline
\end{tabular}

TABLE III. J-C FRACTURE MODEL's CONSTANTS [1]

\begin{tabular}{|c|c|}
\hline Parameter & Value \\
\hline$D_{1}$ & -0.8 \\
\hline$D_{2}$ & 2.1 \\
\hline$D_{3}$ & -0.5 \\
\hline$D_{4}$ & 0.002 \\
\hline$D_{5}$ & 0.61 \\
\hline$\dot{\varepsilon}_{o}$ & $1 \mathrm{~s}^{-1}$ \\
\hline
\end{tabular}




\section{Contact Modelling}

Contact between the cutting insert's rake face and the cutting area of the workpiece, is an important step in the metal cutting process [6]. This contact is also known as the tool chip contact length. The contact is important due to the generated high: stresses, strain rates, and temperatures [6]. Within this contact two regions exist. The regions are known as the sticking and the sliding regions [6]. The sticking region indicates that the shear stress and the critical frictional stress are equal. The sliding region follows Coulomb friction law [6]. The shear stress and the normal stress are proportional in the sliding region.

This numerical model has adopted Coulomb's law as the contact model between the cutting insert and the workpiece. Equation (8), represent the friction used model. In the presented equation, the sliding frictional force and the applied normal load are directionally proportional [13]. $\tau$ is the shear stress, $\sigma$ is the normal stress, and $\mu$ is the coefficient of friction. The coefficient of friction is defined as the ratio between the force parallel to the cutting insert's rake face to the force normal to the rake face. Along the rake face the coefficient of friction is assumed to be constant [14]. The coefficient of friction usually is evaluated experimentally, it ranges between 0.2-1.8 [14]. This numerical model assumes the coefficient of friction to be 0.3 .

$$
\tau=\mu \sigma
$$

\section{EXPERIMENTAL INVESTIGATION}

Down milling experimental investigations were conducted on a 3-axis HAAS VF-2BYT CNC machining center. AISI 4340 steel with hardness of $(47 \pm 1 \mathrm{HRC})$ was used as the workpiece material. A $20 \mathrm{~mm}$ diameter Sandvik CoroMill R390-020A20-11L cylindrical shank was used as the cutting tool. The cutting insert was a PVD coated tungsten carbide Sandvik R390-11T3-04M-PM-1130. Table 4 and Fig. 2 show dimensions of the cutting insert and general configuration of cutting tool and indexable cutting insert, respectively.

TABLE IV. CUTTING ToOL's DimENSIONS $[15,16]$

\begin{tabular}{|c|c|}
\hline Parameter & Value \\
\hline Diameter & $20 \mathrm{~mm}$ \\
\hline Number of Inserts & 2 \\
\hline Axial Rake Angle & $14.5^{\circ}$ \\
\hline Axial Relief Angle & $9^{0}$ \\
\hline Edge Radius & $0.035 \mathrm{~mm}$ \\
\hline Width (W1) & $6.8 \mathrm{~mm}$ \\
\hline Cutting Edge Effective Length (LE) & $10 \mathrm{~mm}$ \\
\hline Corner Radius & $0.40 \mathrm{~mm}$ \\
\hline Wiper Edge Length (BS) & $0.90 \mathrm{~mm}$ \\
\hline Thickness (S) & $3.59 \mathrm{~mm}$ \\
\hline
\end{tabular}

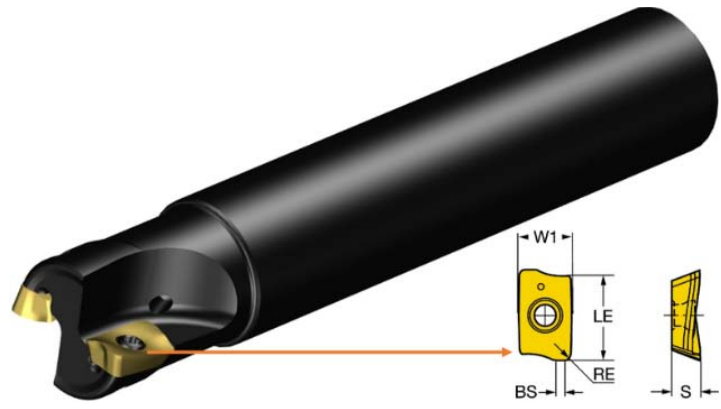

Figure 2. Cutting tool and indexable cutting insert $[15,16]$

Tests were conducted on square shaped blocks of $150 \times$ $150 \times 25 \mathrm{~mm}$. Workpieces were clamped on a 3-axis Kistler piezoelectric dynamometer Type 9255C and three components of milling force in the $x, y$, and $z$ directions were captured during the tests. Milling tests were conducted in the form of a $100 \mathrm{~mm}$ straight lines.

Total of six dry, half immersion, down milling tests were performed at three levels of cutting speed $(75,100,125 \mathrm{~m} /$ $\mathrm{min}$ ) and two levels of feed rate $(800,1000 \mathrm{~mm} / \mathrm{min})$ as the variable cutting conditions. Axial depth of cut and length of each pass were kept constant at $1 \mathrm{~mm}$ and $100 \mathrm{~mm}$ respectively for all tests.

\section{RESUlts AND DISCCSION}

\section{A. Milling Forces}

The cutting forces $\left(F_{x}, F_{y}\right.$, and $\left.F_{z}\right)$ obtained from numerical $3 \mathrm{D}$ finite element model were validated by comparing them to the experimental forces obtained from experiments. Cutting conditions for running the numerical simulation were selected identical to those of machining experiments. Figs. 3-5, present a comparison between the experimental forces and numerical forces for three different cases to display the agreement between the numerical model and experimental results.

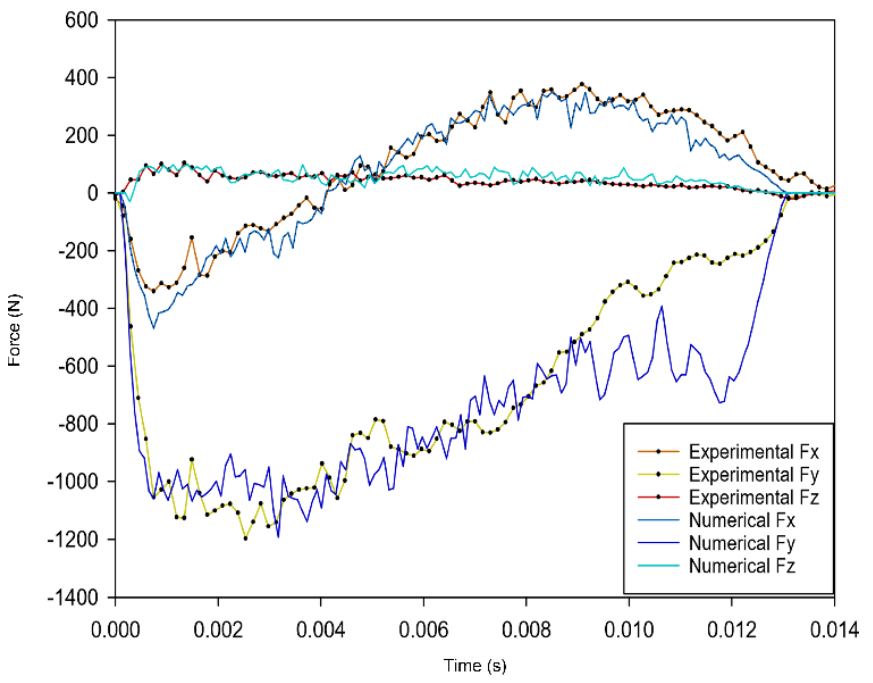

Figure 3. Experimental vs. numerical down milling forces for cutting speed $=$ $75(\mathrm{~m} / \mathrm{min})$ and feed rate $=800(\mathrm{~mm} / \mathrm{min})$ 


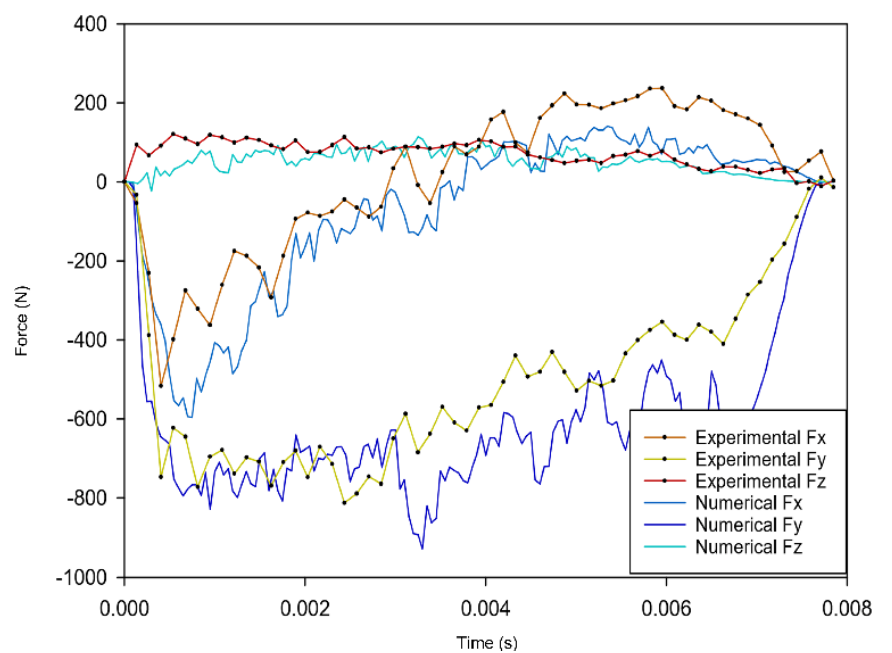

Figure 4. Experimental vs. numerical down milling forces for cutting speed $=$ $125(\mathrm{~m} / \mathrm{min})$ and feed rate $=800(\mathrm{~mm} / \mathrm{min})$

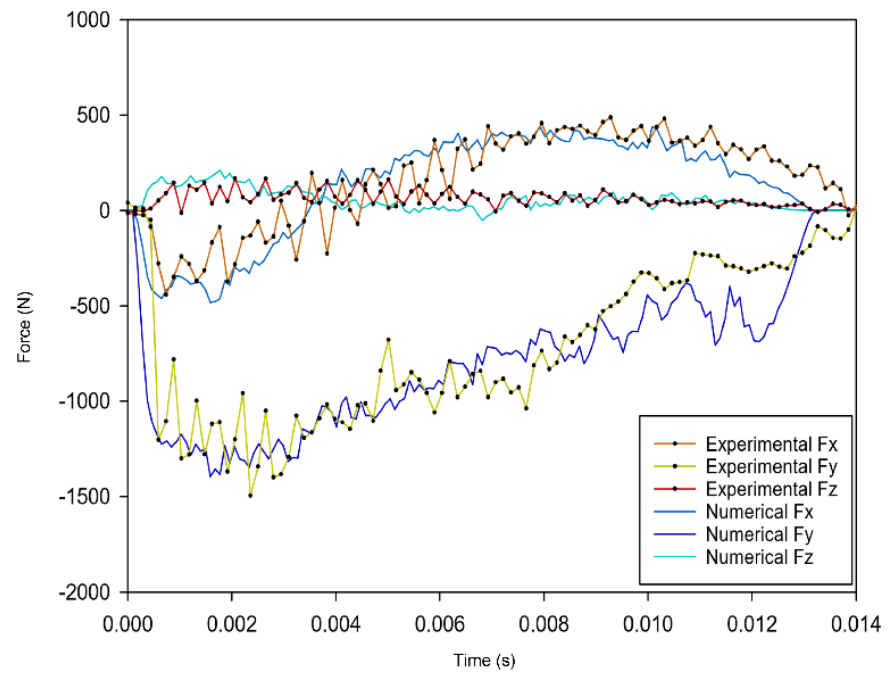

Figure 5. Experimental vs. numerical down milling forces for cutting speed $=$ $75(\mathrm{~m} / \mathrm{min})$ and feed rate $=1000(\mathrm{~mm} / \mathrm{min})$

\section{B. Chip Generation}

During all six experimental tests serrated chips were generated, which is a common case during cutting hardened steels [17]. Serrated chips occur mainly due to two theories, thermos plastic shear instabilities also known as adiabatic shear and/or cyclic cracking [18]. Adiabatic shearing refers to the phenomena where the heat generated during the cutting operation, does not have enough time to dissipate. When heat remains within the primary shear zone, the effects of thermal softening and thermal hardening increase [18]. Increase of the thermal effects results in the localization of the strain within the narrow layers of the primary shear zone. The cyclic cracking is fatigue failure of the chip material [18]. It is a continually increasing structural damage of the generated chip material. Cyclic cracking occurs when high shearing is localized within the primary shear zone. It is assumed that cracks initiates and propagates within the primary shear zone [18].

Fig. 6 displays step by step generation of the serrated chip in the numerical $3 \mathrm{D}$ finite element model. The feed rate and cutting speed for this simulation were $1000 \mathrm{~mm} / \mathrm{min}$ and $75 \mathrm{~m} / \mathrm{min}$, respectively. The shape agreement between the chip generated during milling experiments and the one simulated using finite element enhances the validity of the numerical model.

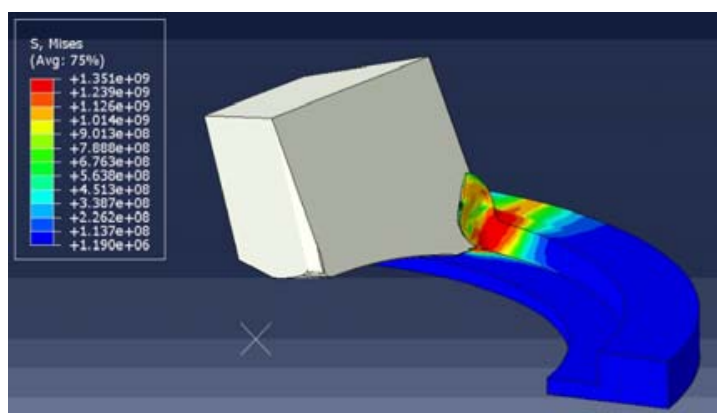

(a) Beginning of the cut

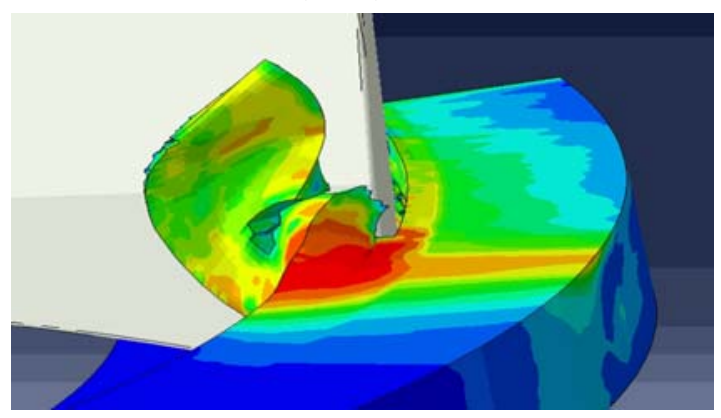

(b) Middle of the cut

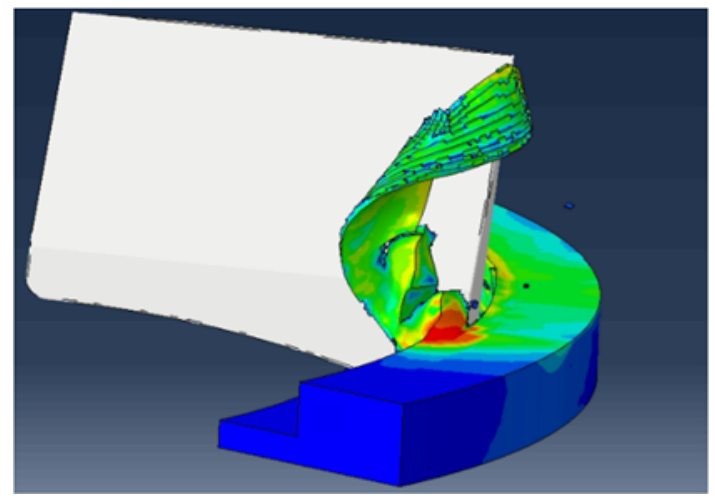

(c) Ending the cut

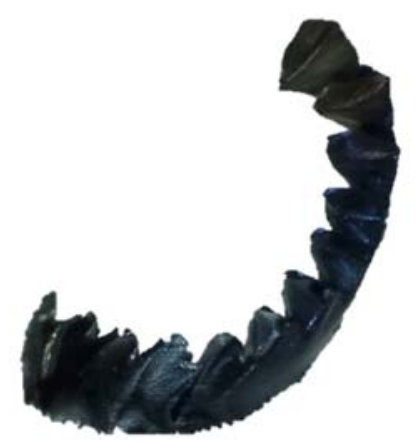

(d) Serrated chip obtained from machining experiments

Figure 6. Comparison between the simulated chip in ABAQUS/Explicit and the chip obtained from machining tests 


\section{CONCLUSION}

A numerical 3D FEA model was presented in this work. The model is able to simulate cutting forces during milling of hardened steels. Indexable milling insert was used as the cutting tool for the model. The numerical model was validated by comparing its results to the results of a series of experimental tests. A close agreement was observed between generated forces from the presented model and the captured forces from the experimental tests. Also, to further validate the model, numerical and experimental chip types were compared, and both presented similar serrated chip shapes.

\section{REFERENCES}

[1] E.-G. Ng, T. I. El-Wardany, M. Dumitrescu, and M. A. Elbestawi, "Physics-based simulation of high speed machining," Machining science and technology, vol. 6, no. 3, pp. 301-329, 2002.

[2] T. Thepsonthi and T. Özel, "3-D finite element process simulation of micro-end milling Ti-6Al-4V titanium alloy: experimental validations on chip flow and tool wear," Journal of Materials Processing Technology, vol. 221, pp. 128-145, 2015.

[3] T. T. Opoz and X. Chen, "Chip formation mechanism using finite element simulation," Strojniški vestnik-Journal of Mechanical Engineering, vol. 62, no. 11, 2016.

[4] G. M. Pittalà and M. Monno, "3D finite element modeling of face milling of continuous chip material," The International Journal of Advanced Manufacturing Technology, vol. 47, no. 5-8, pp. 543-555, 2010.

[5] S. L. Soo, R. C. Dewes, and D. K. Aspinwall, "3D FE modelling of highspeed ball nose end milling," The International Journal of Advanced Manufacturing Technology, vol. 50, no. 9-12, pp. 871-882, 2010.

[6] H. Wu and S. Zhang, "3D FEM simulation of milling process for titanium alloy Ti6A14V," The International Journal of Advanced Manufacturing Technology, vol. 71, no. 5-8, pp. 1319-1326, 2014.

[7] Q. Zhang, S. Zhang, and J. Li, "Three dimensional finite element simulation of cutting forces and cutting temperature in hard milling of AISI H13 steel," Procedia Manufacturing, vol. 10, pp. 37-47, 2017.

[8] G. R. Johnson, "A constitutive model and data for materials subjected to large strains, high strain rates, and high temperatures," Proc. 7th Inf. Sympo. Ballistics, pp. 541-547, 1983.

[9] R. T. Coelho, E.-G. Ng, and M. Elbestawi, "Tool wear when turning hardened AISI 4340 with coated PCBN tools using finishing cutting conditions," International Journal of Machine Tools and Manufacture, vol. 47, no. 2, pp. 263-272, 2007.

[10] S. R. S. S. Kalpakjian, Manufactruing Processes For Engineering Materials Upper Saddle River, New Jersey: Prentice Hall, 2008.

[11] G. R. Johnson and W. H. Cook, "Fracture characteristics of three metals subjected to various strains, strain rates, temperatures and pressures," Engineering fracture mechanics, vol. 21, no. 1, pp. 31-48, 1985.

[12] P. W. Bridgman, Studies in large plastic flow and fracture. McGraw-Hill New York, 1952.

[13] S. Sambedana and T. Jagadeesha, "Finite Element Modelling of Cutting Forces in Face Milling of Duplex Stainless Steel 2205," in Journal of Physics: Conference Series, 2019, vol. 1240, no. 1: IOP Publishing, p. 012151.
[14] A. Priyadarshini, S. K. Pal, and A. K. Samantaray, "Influence of the Johnson Cook material model parameters and friction models on simulation of orthogonal cutting process," Journal of Machining and Forming Technologies, vol. 4, no. 1/2, pp. 59-83, 2012.

[15] "CoroMill $\mathbb{R} 390$ insert for milling-R390-11 T3 04M-PM 1130." SANDVIK Coromant. https://www.sandvik.coromant.com/en$\mathrm{gb} /$ products/pages/productdetails.aspx? $\mathrm{c}=\mathrm{r} 390-11 \% 20 \mathrm{t} 3 \% 2004 \mathrm{~m}$ pm\%201130\&gclid=EAIaIQobChMIzonGwf_g5wIVjNkCh1pxggqEAAYASAAEgKP_PD_BwE (accessed 2020).

[16] "CoroMill $(\mathrm{R} 390$ square shoulder milling cutter-R390R390-020A2011L." SANDVIK Coromant. https://www.sandvik.coromant.com/en$\mathrm{gb} /$ products/pages/productdetails.aspx?c=R390-020A2011L\&gclid=EAIaIQobChMIspiw5v7g5wIVsSCtBh2NVA5REAAYAS AAEgKhEvD_BwE (accessed 2020).

[17] S. Soo, D. Aspinwall, and R. Dewes, "3D FE modelling of the cutting of Inconel 718," Journal of Materials Processing Technology, vol. 150, no. 1-2, pp. 116-123, 2004.

[18] H. A. Kishawy and A. Hosseini, Machining Difficult-to-Cut Materials: Basic Principles and Challenges. Springer, 2018. 